DOI: $10.5455 / 2320-1770.1 j \operatorname{cog} 20150419$

Research Article

\title{
Breech delivery: changing scenario
}

\section{Sanjivani Anil Wanjari*}

Department of Obstetrics \& Gynaecology, Lata Mangeshkar Hospital Extended Teaching Programme at Daga Hospital, Nagpur, Maharashtra, India

Received: 28 January 2015

Revised: 15 February 2015

Accepted: 16 February 2015

\section{*Correspondence:}

Dr. Sanjivani Anil Wanjari,

E-mail: sanjivaniwanjari@yahoo.com

Copyright: ( ) the author(s), publisher and licensee Medip Academy. This is an open-access article distributed under the terms of the Creative Commons Attribution Non-Commercial License, which permits unrestricted non-commercial use, distribution, and reproduction in any medium, provided the original work is properly cited.

\begin{abstract}
Background: In context of the debate surrounding the optimal mode of delivery for the breech, we did a retrospective study in our hospital. The aim of the study was to assess the mode of delivery, to analyze the indications for caesarean section and to find out the perinatal outcome in breech during the study period.

Methods: A retrospective study was done of women with breech admitted to our unit at Daga hospital Nagpur. All women having viable breech pregnancies of more than 34 weeks gestation were included in the study. An effort was done to find out whether mode of delivery affected neonatal outcome.

Results: Although it is not our policy to have an elective planned caesarean section for all breech presentations, there was a high rate of caesarean section for breech. Most of the caesarean sections were in primigravida having a breech presentation (58.62\%). Nearly $92 \%$ of women in the study group were in the age group of 20 to 30 years. A high caesarean section rate in a young population can have implications in future pregnancies.

Conclusions: There is an on-going debate about the best way to deliver breeches. The policy of planned caesarean section for breech may not be feasible in all hospitals and by choice or default, vaginal breech births will continue to take place, which means attention is still warranted to skills and techniques that may improve outcomes for the baby.
\end{abstract}

Keywords: Vaginal breech delivery, Caesarean section, Perinatal mortality

\section{INTRODUCTION}

About $3-4 \%$ of all pregnancies reach term with a foetus in the breech presentation. ${ }^{1}$ Vaginal deliveries for breech presentations have long been a topic of debate. ${ }^{2}$ The management of breech presentation remains an area of intense controversy. Various options are External Cephalic Version (ECV), planned caesarean section and vaginal delivery. There has been an increasing reluctance for vaginal delivery in many centres. The main reason is difficulty in the passage of the unmolded after-coming head of breech. Compared with a foetus with cephalic presentation, a breech foetus faces increased risk during labour and delivery. There is risk of asphyxia from cord compression and delay in delivery of the after-coming head and of traumatic injury during delivery of the shoulders and head.

The debate surrounding the optimal mode of delivery for the breech foetus focuses on a single clinical question: what is the magnitude of risk to the foetus of a trial of labour and how should we balance it against the increased immediate and future risk of caesarean section to the mother and her future children?

Some authors have advocated liberal use of caesarean section in an effort to reduce perinatal mortality \& morbidity associated with term breech delivery. Data from previously published cohort studies have shown that, in general, planned caesarean section is better than planned vaginal birth for the foetus that presents as a 
breech at term. ${ }^{3,4}$ At the same time according to others, resorting to caesarean section in every case of breech presentation does not eliminate all the risks associated with breech., ${ }^{5,6}$ In general a breech presentation irrespective of mode of delivery is associated with an increased risk of subsequent infant physical or mental disability. $^{7}$

In the context of the above data we decided to do a retrospective analysis of hospital data to find out the status of breech delivery at our hospital.

The aims of the study were:

1) To find out the incidence of breech during the study period.

2) To assess the mode of delivery.

3) To analyze the indications for caesarean section.

4) To find out the perinatal outcome in breech during the study period.

\section{METHODS}

A retrospective study of women with breech admitted in our unit was done at Daga hospital Nagpur from $1^{\text {st }}$ January 2013 to $30^{\text {th }}$ June 2014. All women having viable breech pregnancies of more than 34 weeks gestation were included in the study. Pregnancies with intrauterine foetal death and congenital anomalies were excluded from the study. An effort was done to assess the mode of delivery and reasons for caesarean section and to find out whether mode of delivery affected neonatal outcome.

\section{RESULTS}

It is not our policy to have an elective planned caesarean section for all breech presentations at our hospital. However in the retrospective analysis we found that $74 \%$ of breech pregnancies were delivered by caesarean section. Out of total of 116 breech births, 86 were caesarean sections and only 30 delivered vaginally. Most of the caesarean sections were in primigravida having a breech presentation $(58.62 \%)$. The other common reasons for caesarean section were prior caesarean section (10.34\%), and associated factors like PIH (3.44\%), PROM (7.75\%), non-progress of labour (5.17\%), and post-dated pregnancy $(4.31 \%)$ and severe oligohydramnios $(2.58 \%)$.

The incidence of breech on our study was similar to the overall standard of $4 \%$. Nearly $92 \%$ of women in the study group were in the age group of 20 to 30 years. A high caesarean section rate in a young population can have implications in future pregnancies.

Most of the neonates having asphyxia at birth were from the normal breech delivery category. A total of 9 neonates had admissions to NICU, out of which 8 were vaginal breech deliveries and only one was delivered by caesarean section. Later 7 neonates were discharged in good condition. There were two neonatal deaths in our study which were mainly due to respiratory distress, prematurity and sepsis. There was no maternal death in our study. Maternal morbidity was found in two women. One had post-operative fever secondary to PROM of 4 days and another woman with previous scar had scar dehiscence and required two units of blood transfusion.

Table 1: Age distribution.

\begin{tabular}{|lllll|}
\hline \multirow{2}{*}{ Age } & \multicolumn{2}{l}{$\begin{array}{l}\text { Caesarean } \\
\text { section }\end{array}$} & \multicolumn{2}{l|}{$\begin{array}{l}\text { Vaginal } \\
\text { delivery }\end{array}$} \\
& No. & $\mathbf{\%}$ & No. & \% \\
\hline <20 years & 2 & 1.72 & 3 & 2.58 \\
\hline 20-25 years & 56 & 48.27 & 17 & 14.65 \\
\hline 26-30 years & 25 & 21.55 & 9 & 7.75 \\
\hline$>$ 30 years & 3 & 2.58 & 1 & 0.86 \\
\hline
\end{tabular}

Table 2: Parity distribution.

\begin{tabular}{|lllll|}
\hline \multirow{2}{*}{ Parity } & \multicolumn{2}{l}{ Caesarean } & \multicolumn{2}{l|}{ Vaginal } \\
section & \multicolumn{2}{c|}{ delivery } \\
& No. & \% & No. & \% \\
\hline G1 & 68 & 58.62 & 5 & 4.31 \\
\hline G2 & 16 & 13.79 & 11 & 9.48 \\
\hline G3-G5 & 2 & 1.72 & 14 & 12.06 \\
\hline
\end{tabular}

Table 3: Fetomaternal outcome.

\begin{tabular}{|c|c|c|c|c|}
\hline \multirow{2}{*}{$\begin{array}{l}\text { Fetomaternal } \\
\text { outcome }\end{array}$} & \multicolumn{2}{|c|}{$\begin{array}{l}\text { Caesarean } \\
\text { section }\end{array}$} & \multicolumn{2}{|c|}{$\begin{array}{l}\text { Vaginal } \\
\text { delivery }\end{array}$} \\
\hline & No. & $\%$ & No. & $\%$ \\
\hline $\begin{array}{l}\text { Short term neonatal } \\
\text { morbidity }\end{array}$ & 0 & 0 & 7 & 6.03 \\
\hline Neonatal mortality & 1 & 0.86 & 1 & 0.86 \\
\hline Maternal morbidity & 2 & 1.72 & 0 & 0 \\
\hline Maternal mortality & 0 & 0 & 0 & 0 \\
\hline
\end{tabular}

\section{DISCUSSION}

During the past decade, there has been an increasing trend in the United States to perform caesarean delivery for term singleton foetuses in a breech presentation. ${ }^{8}$ This was also found true in our study, where there was a high prevalence of caesarean section for term breech pregnancies. A large chunk of cases in our study were primigravida $(58.62 \%)$ and there was a general reluctance to deliver primigravida with breech presentation vaginally. Such a large percentage of women having a primary caesarean section may encounter problems in subsequent deliveries like uterine rupture or abnormal placentation. Women with at least one prior birth had associated factors like PROM, PIH, prior scar, post-dated pregnancy, non-progress of labour and oligohydramnios, which may have contributed for the decision for caesarean section. 
In 2000, researchers conducted a large, international multicenter randomized clinical trial comparing a policy of planned caesarean delivery with planned vaginal delivery (Term Breech Trial). ${ }^{3}$ The Term Breech Trial was the largest randomized controlled trial to investigate the effect of mode of delivery for term breech deliveries on neonatal and maternal outcomes. The study reported a highly significant decrease in combined perinatal mortality and morbidity scores among women undergoing a planned caesarean compared with those planned to deliver vaginally [5.0\%o vs. $16.0 \%$, relative risk (RR) 0.33 ; 95\% confidence interval (CI) $0.19-0.56]$. In our study too most of the cases of birth asphyxia and admissions to NICU were in vaginal breech deliveries. Short term neonatal morbidity was more in the vaginal delivery group versus the babies delivered via caesarean section.

Subsequent to the publication of the Term Breech Trial, there have been a number of published accounts of the effect of planned elective caesarean section for term breech presentation on whole populations. A review of the Dutch perinatal database showed that the rate of planned elective caesarean section for term breech changed from $49 \%$ in the 33 months prior to the publication of the Term Breech Trial to $80 \%$ in the 25 months afterwards. ${ }^{9}$ The analysis included more than 33 000 infants. This change led to a halving of the perinatal mortality rates and rates of low Apgar scores, as well as the rates of birth trauma, which fell by three-quarters.

A more recent trial, the PREMODA (Presentation ET Mode d'Accouchement: presentation and mode of delivery) study produced different findings. ${ }^{10}$ The PREMODA trial which is often referred to as the "antidote to the Term Breech Trial" was conducted in France and Belgium. They used the same criteria and outcome measures as the Term Breech Trial (TBT), except the decision for a Caesarean Section (CS) or Vaginal Breech Birth (VBB) was the woman's, not randomized. The PREMODA study investigated 3 groups: planned CS, planned VBB, and unplanned CS during a planned VBB. In total there were 8,105 women in the study. $28 \%$ of planned VBB ended in a caesarean during labour. They had much less crossover in the planned CS arm $(<1 \%)$ than in the TBT $(10 \%)$. PREMODA did not find a significant excess risk associated with planned vaginal delivery compared with planned caesarean for women with a singleton foetus in breech presentation at term. In light of the PREMODA study, some obstetricians have been calling for a return to breech vaginal delivery.

Another implication of an 'elective caesarean for all' policy is the negative impact on training, further reducing the number of practitioners with the skills and experience necessary to deliver a breech vaginally, safely. Even in academic medical centres where faculty support for teaching vaginal breech delivery to residents remains high, there may be insufficient volume of vaginal breech deliveries to adequately teach this procedure. ${ }^{11}$
In light of the recent publications the American college of obstetricians and gynaecologists committee on obstetric practice issued the following recommendations: The decision regarding the mode of delivery should depend on the experience of the health care provider. Caesarean delivery will be the preferred mode of delivery for most physicians because of the diminishing expertise in vaginal breech delivery. Obstetricians should offer and perform external cephalic version whenever possible. Planned vaginal delivery of a term singleton breech foetus may be reasonable under hospital-specific protocol guidelines for both eligibility and labour management. In those instances in which breech vaginal deliveries are pursued, great caution should be exercised. Before embarking on a plan for a vaginal breech delivery, women should be informed that the risk of perinatal or neonatal mortality and the patient's informed consent should be documented. ${ }^{12}$

\section{CONCLUSION}

Controversy surrounding the best approach by which to deliver breech babies has coincided with and contributed to the overall rising caesarean section rates over the last 50 years. Evidence from the Term Breech Trial and a Cochrane review impacted greatly on the shift towards caesarean section being performed when breech presentation was diagnosed. However, there is an ongoing debate about the validity of these findings and in general, the risks of caesarean section upon the woman's health, as it is associated with increased maternal morbidity, mortality and risks to subsequent pregnancies. The question arises as to how many countries can sustain a planned caesarean section policy for breech presentation and for how long? Also by choice or default, vaginal breech births will continue to take place, which means attention is still warranted to skills and techniques that may improve outcomes for the baby. It is therefore necessary that women with breech should receive adequate antenatal care and proper assessment by experienced obstetricians in order to decide the mode of delivery. Regular teaching using video clips \& practising with mannequins will be necessary to preserve the skills of vaginal breech delivery.

\section{ACKNOWLEDGEMENTS}

I would like to thank Dr. Farooqui- medical superintendent at Daga hospital Nagpur for his support and encouragement and for allowing us to conduct the study.

\section{Funding: No funding sources \\ Conflict of interest: None declared \\ Ethical approval: Not required}

\section{REFERENCES}

1. Hickok DE, Gordon DC, Milberg JA, Williams MA, Daling JR. The frequency of breech presentation by 
gestational age at birth: a large population-based study. Am J Obstet Gynecol. 1992;166:851-2.

2. Cheng M, Hannah M. Breech delivery at term: a critical review of the literature. Obstet Gynecol. 1993;82:605-18.

3. Ref-Hannah ME, Hannah WJ, Hewson SA, Hodnett ED, Saigal S, Willan AR. Planned caesarean section versus planned vaginal birth for breech presentation at term: a randomised multicentre trial. Term Breech Trial Collaborative Group. Lancet. 2000;356:137583.

4. Gifford DS, Morton SC, Fiske M, Kahn K. A metaanalysis of infant outcomes after breech delivery. Obstet Gynecol. 1995;85:1047-54.

5. Gini Njoku O. The outcome of breech delivery. Trop J Obstet Gynaecol. 1987;8(2):15-8.

6. Myers SA, Gleicher N. Breech delivery: why the dilemma? Am J Obstet Gyanecol. 1980;137:235.

7. Danielian P, Wang J, Hall M. Long-term outcome by method of delivery of foetuses in the breech presentation at term: population-based follow-up. BMJ. 1996;312:1451-3.

8. Martin JA, Hamilton BE, Sutton PD, Ventura SJ, Menacker F, Munson ML. Births: final data for 2002. Natl Vital Stat Rep. 2003;52(10):11-3.
9. Rietberg CC, Elferink-Stinkens PM, Visser GH. The effect of the Term Breech Trial on medical intervention behaviour and neonatal outcome in The Netherlands: an analysis of 35453 term breech infants. BJOG. 2005;112:205-9.

10. Goffinet F, Carayol M, Foidart JM, Alexander S, Uzan S, Subtil D, et al. PREMODA Study Group. Is planned vaginal delivery for breech presentation at term still an option? Results of an observational prospective survey in France and Belgium. Am J Obstet Gynecol. 2006;194:1002-11.

11. Lavin JP Jr, Eaton J, Hopkins M. Teaching vaginal breech delivery and external cephalic version. A survey of faculty attitudes. J Reprod Med. 2000;45:808-12.

12. American College of Obstetricians and Gynaecologists. ACOG Committee Opinion No. 340. Mode of term singleton breech delivery. Obstet Gynecol. 2006;108:235-7.

DOI: $10.5455 / 2320-1770$. ijrcog20150419

Cite this article as: Wanjari SA. Breech delivery: changing scenario. Int J Reprod Contracept Obstet Gynecol 2015;4:384-7. 